Platelet Microvesicles (Microparticles) In Cardiac Surgery

Jake A. Tempo BMBS BMedSc, Nicola A. Englyst BSc PhD PCAP, Judith A. Holloway BSc PhD PG Cert, David C. Smith BMBS BMedSc DM

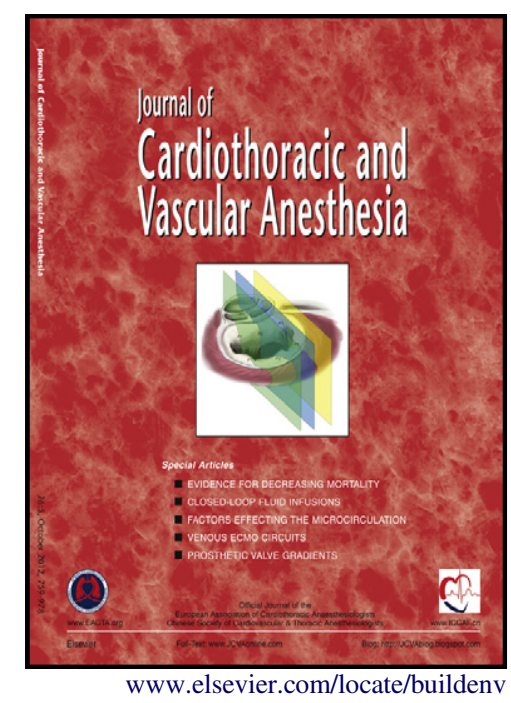

PII:

S1053-0770(15)00746-6

DOI: http://dx.doi.org/10.1053/j.jvca.2015.08.001

Reference: YJCAN3387

To appear in: Journal of Cardiothoracic and Vascular Anesthesia

Cite this article as: Jake A. Tempo BMBS BMedSc, Nicola A. Englyst BSc PhD PCAP, Judith A. Holloway BSc PhD PG Cert, David C. Smith BMBS BMedSc DM, Platelet Microvesicles (Microparticles) In Cardiac Surgery, Journal of Cardiothoracic and Vascular Anesthesia, http://dx.doi.org/10.1053/j.jvca.2015.08.001

This is a PDF file of an unedited manuscript that has been accepted for publication. As a service to our customers we are providing this early version of the manuscript. The manuscript will undergo copyediting, typesetting, and review of the resulting galley proof before it is published in its final citable form. Please note that during the production process errors may be discovered which could affect the content, and all legal disclaimers that apply to the journal pertain. 


\section{Platelet microvesicles (microparticles) in cardiac surgery}

Jake A Tempo ${ }^{1}$ BMBS BMedSc, Nicola A Englyst ${ }^{1}$ BSc PhD PCAP, Judith A Holloway ${ }^{1}$ BSc PhD PG Cert, David C Smith² BMBS BMedSc DM

1. Faculty of Medicine, University of Southampton, UK

2. Department of Anaesthetics, Southampton General Hospital, UK

Corresponding author:

Dr Jake Tempo

Flat 3, 13 Priory Avenue, Southampton S017 2NN, United Kingdom

jake_tempo@hotmail.co.uk_jt10g10@soton.ac.uk

\section{Southampton}

\section{Acknowl edgemen \\ ts}

University Hospital Southampton W/HS

NHS Foundation Trust

Our research group has received funding from the following organisations for our ongoing studies into the impact of cardiac surgery upon microvesicle populations:

European Association of Cardiothoracic Anaesthesiologists

Association of Cardiothoracic Anaesthetists (UK)

Gerald Kerkut Charitable Trust

Keywords: platelet microvesicles; microvesicles; microparticles; cardiac surgery; cardiopulmonary bypass; platelets; thrombocytes 


\section{Introduction}

Significant postoperative bleeding is a common risk of cardiac surgery with approximately $3.5 \%$ of patients requiring surgical re-exploration. ${ }^{1}$ Re-exploration is associated with adverse outcomes including infections, ischemia, and increased 30-day mortality. ${ }^{2}$ Similar adverse outcomes are related to erythrocyte transfusions associated with cardiac surgery, ${ }^{3}$ in addition to the immunologic and administrative hazards of transfusion. ${ }^{4}$ These risks are important because the majority of patients undergoing cardiac surgery receive a blood transfusion despite the lack of evidence to support liberal transfusion strategies. ${ }^{5}$ The frequency and significance of bleeding following cardiac surgery warrants investigation of the hematologic changes throughout the procedure. This review focuses on the (patho)physiology of platelet-derived microvesicles in the setting of cardiovascular surgery, a developing area in our understanding of the control of coagulation.

\section{Microvesicle physiology}

Microvesicles, formerly called microparticles, ${ }^{6,7}$ are released from the cell membrane of a range of cells, including monocytes, erythrocytes and endothelial cells, during activation or apoptosis. ${ }^{8,9}$ They are $10-200 \mathrm{~nm}$ in diameter and retain surface antigens specific to their parent cell. Platelet microvesicles (PMV) are the most abundant in normal plasma. ${ }^{7,10} \mathrm{PMV}$ have an important role in the initiation and propagation of coagulation, providing a key focus for hematologic research to improve the safety of cardiac surgery. Their discovery occurred when the clotting time of blood was prolonged following high-speed centrifugation during which PMV became separated from platelet-dense serum, suggesting that PMV enhance coagulation. ${ }^{11}$ Further research using centrifugation and electron microscopy revealed that activated platelets produced a phospholipid-rich 'platelet dust' which had a role in thrombin generation. ${ }^{12}$ 


\section{Production of PMV}

Following endothelial injury, inflammatory mediators including glycoprotein Ib/IX and endothelial von Willebrand factor (vWf) trigger a rise in cytosolic calcium which stimulates calpain to trigger platelet activation and the release of adenosine diphosphate (ADP), thrombin, tissue factor (TF) and thromboxane $\mathrm{A}_{2} \cdot{ }^{9}$ (Figure 1).

In the non-activated state the phospholipid bi-layer of the platelet membrane is held in asymmetry as a result of the enzyme transporters flippase and aminophospholipid translocase. ${ }^{13} \mathrm{~A}$ rise in cytosolic calcium following platelet activation has a key role in the production of PMV through its action on these enzymes (Figure 2). Flippase and aminophospholipid translocase are inhibited, disabling them from holding phosphatidylserine (PS) and phosphatidylethanolamine on the inner membrane layer, ${ }^{14}$ while activation of floppases and lipid scramblase causes rapid outward translocation of PS and loss of membrane asymmetry. ${ }^{15,16}$ The movement of PS to the outer surface of the platelet membrane activates factor $X$ and prothrombin, thus propagating the coagulation cascade and the formation of PMV. ${ }^{17,18}$

In addition to the loss of membrane asymmetry, activation of gelsolin and calpain causes is alteration of the platelet actin cytoskeleton and a change in platelet shape, which in itself produces PMV. ${ }^{19,20}$ However, PMV are still produced when calpain is inhibited. ${ }^{21}$ There are consequentially multiple pathways to PMV production, and disabling one pathway may still allow PMV to be shed.

\section{Procoagulant activity}

The inability to produce lipid scramblase in Scott syndrome results in platelets that are unable to lose membrane asymmetry to allow surface expression of PS and form microvesicles. ${ }^{9}$ Platelets have rapid PS expression, allowing prompt promotion of coagulation at the sites of endothelial injury: ${ }^{18}$ the removal of PS from the PMV surface decreases the rate of thrombin production, ${ }^{22}$ providing evidence that the production of PMV 
is critical to physiological coagulation. The phenotype of a microvesicle alters its function; increasing expression of PS and TF enhances thrombin generation. ${ }^{22}$ Some PMV express anti-coagulant receptors, suggesting there may be a role for PMV in regulating hemostasis. ${ }^{23}$ Procoagulant receptors are more densely expressed on the surface of PMV than the parent platelet by up to 100 -fold. ${ }^{24}$ Increased concentrations of circulating PMV promote platelet aggregation, leading to thrombus formation. ${ }^{25} \mathrm{PS}$ expression on the outer surface of the microvesicle encourages coagulation due to its ability to bind and stimulate several coagulation factors through the interaction with their gamma-carboxyglutamic acid domains. These factors include factors IIa, Va, VIII, IXa (Figure 3). ${ }^{26}$ TF expressed on the surface of PMV initiates coagulation by activating factor VII to recruit platelets and initiate the pathway to thrombus formation in the response to vascular injury. ${ }^{27}$ However increased TF expression does not always correlate with increased coagulation, suggesting that other factors are similarly important. ${ }^{22,28}$ Integrin $\alpha_{11 b} \beta_{3}$, another receptor expressed on the outer PMV surface, has a role in binding PMV to fibrinogen to cause platelet adhesion. ${ }^{29}$

Microvesicles taken from the pericardial cavity of patients undergoing cardiopulmonary bypass promote thrombin generation..$^{30}$ Berckmans et al demonstrated that the introduction of microvesicles in vitro to plasma results in thrombin generation. ${ }^{26}$ Interestingly, they proposed that small amounts of thrombin generate activated protein C (APC), which can have anticoagulant properties by inactivating factors Va and $\mathrm{VIIIa} .{ }^{26} \mathrm{PMV}$ also support APC generation, which leads to a hypothesis that PMV have a role in homeostasis in thrombosis by possessing both anti- and pro-coagulant triggering mechanisms. ${ }^{23,31}$

\section{Clearance}

The first report investigating the half-life of transfused PMV in vivo demonstrated a plasma half-life of under six hours in 11 patients with thrombocytopenia awaiting platelet transfusion. ${ }^{32}$ This is faster than the rate of circulating platelet clearance. Microvesicles released following dobutamine stress echocardiography are cleared from the circulation 
within an hour. ${ }^{33}$ These studies suggest that microvesicles exert their actions in a very short time-frame and that there exists separate pathways for microvesicle and platelet clearance. There are significantly higher numbers of circulating microvesicles in splenectomised mice versus non-splenectomised mice, suggesting that the spleen is the site of microvesicle clearance. ${ }^{34}$ Following opsonisation of microvesicles, macrophages can then phagocytose particles up to $2 \mu \mathrm{m}$ in size. ${ }^{35}$ The process is very rapid, with maximum uptake occurring at one hour.

Platelet microvesicles decline more gradually in thawed fresh frozen plasma, by $50 \%$ over five days. The resulting decline in procoagulant activity was $29 \%$, indicating that PMV numbers decrease in vitro and contribute to in vivo coagulation. ${ }^{10}$ The same study also demonstrated that removal of PMV by filtration results in reduced thrombin generation, and that restoration of PMV into the infusion increased the ability for coagulation. The cause of PMV decline in vitro is only speculated; Matijevic et al suggests that extacellular phospholipases may degrade the microvesicles to sub-detectable volumes or that microvesicle coupling to other microvesicles or platelets occurs, forming larger aggregates. ${ }^{36}$ The decline in microvesicle numbers may have been a result of proteases degrading antibodies on the vesicle surface over time therefore creating an apparent decline in numbers.

\section{Laboratory tests and PMV}

The standard method for monitoring coagulation during CPB is the Activated Clotting Time (ACT) of whole blood. However, this has poor reproducibility, with variation between activators and between devices, and has no correlation with heparin concentration. ${ }^{37,38}$ ACT has no role in evaluation of platelet or PMV function. The activated partial thromboplastin time and the prothrombin time are used in laboratory practice to assess the intrinsic and extrinsic coagulation pathways respectively, but since they are performed on cell-free plasma neither of these tests is sensitive or specific enough for the complete assessment of 
either perioperative coagulation status or PMV activity. Tests of the visco-elastic properties of whole blood, such as thromboelastography, allow more precise evaluation of perioperative coagulopathy, however thromboelastography does not seem to be effective at analysing PMV populations. ${ }^{39}$ The standard method for evaluating PMV is flow cytometry (see below), but this is not currently available as a point-of-care test.

\section{Pharmaceutical influences}

Antiplatelet agents

Antiplatelet drug use before cardiac surgery increases bleeding complications. ${ }^{40,41}$ Aspirin inhibits cyclooxygenase-1 derived thromboxane $A_{2}$ in platelets, limiting cytosolic calcium increases to reduce aggregation. Aspirin ingestion for seven days does not affect either the number or surface expressions of PMV. ${ }^{42}$ Clopidogrel acts through the inhibition of ADPinduced aggregation. ADP produced from activated platelets triggers G-protein coupled receptors to increase cytosolic calcium to cause PMV production. ${ }^{43}$ Clopidogrel use in the 24 hours prior to cardiac surgery has an odds ratio of 2.4 for excessive bleeding compared to patients not receiving clopidogrel. ${ }^{40}$ The plasma concentration of clopidogrel is inversely proportional to the number of PMV in patients with stable coronary artery disease,

suggesting clopidogrel reduces the production of PMV. ${ }^{44}$ Similarly, plasma endothelial microvesicle numbers are reduced after administration of clopidogrel. ${ }^{45}$ However, one study found that anti-platelet drugs did not have an effect on populations of circulating PMV. ${ }^{46}$ These conflicting results warrant further investigation into the effect of antiplatelet agents on PMV populations.

\section{Anticoagulants}

Heparin inhibits thrombin via anti-thrombin III, but does not affect surface-bound thrombin. ${ }^{47}$ Muriithi et al found that a delayed heparin-induced impairment of platelet aggregation occurs in patients prior to CPB, which may suggest that platelet defects previously thought to be solely the result of passage through the bypass circuit may result from interaction with 
heparin. ${ }^{48}$ Although Muriithi's study did not investigate PMV, their formation occurs simultaneously with platelet activation and therefore heparinisation may result in decreased PMV numbers.

\section{Anesthetics and other drugs}

Currently no studies have investigated the effect of propofol or volatile anesthetics on PMV populations, however propofol does inhibit both intra-operative and post-operative platelet aggregation. ${ }^{49,50}$ Given the hemodynamic effects of anesthetic drugs, changes in shear stress within the circulation may be expected to modify platelet and PMV behaviour, but there are no published data on how this may affect PMV. Statins have no effect on PMV numbers. ${ }^{44,46}$

\section{Intravenous fluids}

A variety of crystalloid and colloid fluids, and blood components, are administered during surgery and CPB. Hemodilution reduces blood viscosity, allowing potentially faster blood flow and increased shear stresses within the cardiovascular system. However, there are no published data on how this might affect PMV.

\section{Microvesicles in health and disease}

Females have more circulating PMV than males, although this difference is reduced following the menopause. ${ }^{7}$ Low or normal levels of PMV occur in pre-eclampsia, while systemic lupus erythematosus, paroxysmal nocturnal hemoglobinuria, myeloproliferative diseases, venous thromboembolism, diabetes mellitus, acute coronary syndrome, and chronic renal failure result in raised PMV numbers. ${ }^{51}$ 


\section{PMV in cardiac surgery \\ Cardiopulmonary bypass}

The process of CPB induces hematologic changes via various pathways, including the passage of blood through the circuit causing activation of coagulation factors, adhesion of blood components to the circuit, and hemodilution as the priming solution mixes with the patient's blood. The effect of CPB on coagulation is significant; excessive bleeding is more common in patients undergoing on-pump cardiac surgery than in those undergoing off-pump cardiac surgery. ${ }^{52}$ However, circulating fresh blood through a miniaturized CPB circuit does not stimulate PMV production, ${ }^{53}$ suggesting that surgical trauma is more of a stimulus to PMV production than CPB.

\section{Shear stress}

Cardiopulmonary bypass is usually performed with roller pumps, rather than centrifugal pumps, despite the generation of shear forces that can cause hemolysis, and spallation of the pump head tubing. ${ }^{54,55}$ There is no evidence favoring either type of pump in terms of hematologic or coagulation parameters, postoperative blood loss, blood transfusion, neurologic outcome, or mortality, ${ }^{41,56-58}$ since the effects of antifibrinolytic drugs and mild hypothermia probably overshadow any small differences between pump types. ${ }^{41}$ However, damage to platelets and red cells, and the inflammatory response, may be worse with prolonged CPB using roller pumps. ${ }^{56,59,60}$ Shear stress causes the platelets to bind $\mathrm{vWf}^{61}$ the surrounding hydrodynamic forces inducing change in platelet shape, ${ }^{62}$ and hence the production of PMV, but there are no published data on the effect of pump type on PMV.

\section{Adhesion}

Despite complement activation during CPB, PMV numbers decrease even after hemodilution is accounted for. ${ }^{63}$ These findings suggest that adhesion to the circuit, ${ }^{64,65}$ or recruitment to thrombus formation within the surgical field, decreases the PMV population faster than they are being produced. The thrombogenic surface of the CPB circuit encourages platelet 
activation and the production of $\mathrm{PMV},{ }^{66}$ though this effect is reduced with bio-compatible coatings in the CPB circuit. ${ }^{67}$ Fibrin and fibrinogen adhere to the surface, causing thrombin to be deposited, which then binds platelet receptors causing their deposition on the circuit surface. ${ }^{62} \mathrm{PMV}$ bind to collagen type I, fibrinogen, $\mathrm{vWf}$, and also to immobilized platelets already bound to thrombogenic surfaces. Due to the sub-micron size of PMV, they may be able to withstand extreme shear stress, remaining in position to encourage further thrombus formation on extra-corporeal surfaces. ${ }^{68}$

\section{Hemodilution}

The prime fluid mixes with circulating blood, diluting coagulation factors both during bypass and in the immediate post-bypass period. ${ }^{69}$ As mean arterial pressure is low during CPB there is an increased risk of thrombotic events during this time, counteracted by the reduction in pro-coagulant substances, cells and PMV by hemodilution. The risk of adverse hematologic events occurs post-operatively when these key players in the coagulation cascade have not recovered to pre-bypass levels, leading to a coagulopathy.

\section{Cell salvage}

Mechanical cell salvage removes the majority of platelets and virtually all $\mathrm{PMV},{ }^{70}$ since PMV and coagulation factors are removed in the washing process. Despite this reduction, the adverse event incidence following autotransfusion is $0.027 \%$ in contrast to $0.14 \%$ with allogeneic blood transfusions. ${ }^{71}$ However, postoperative platelet counts two hours after CPB are the same between control and cell-salvaged patients, although postoperative blood loss was less in patients who had received cell-salvaged blood. ${ }^{72}$ Further work is required to elucidate the pattern of PMV activity during cardiac surgery and the potential impact on perioperative coagulation. 


\section{Surgical trauma}

Surgical trauma causes endothelial and soft tissue injury which leads to PMV formation. ${ }^{51,73-}$

${ }^{75}$ The result is platelet recruitment, and subsequent thrombus formation. Surgical trauma increases microvesicle production in cardiac surgery in addition to the effect of $C P B$, since pericardial blood contains higher concentrations of coagulation markers and microvesicles than blood in the left ventricle..$^{64,65,76}$

\section{Left ventricular assist devices}

There are no published data on PMV formation in implanted LV assist devices, although bleeding and thrombosis are a significant risk in this population. ${ }^{77}$

\section{Hypothermia}

Hypothermia below $31.3^{\circ} \mathrm{C}$ during cardiac surgery is associated with decreased platelet function and decreased formation of PMV in heparinised blood, leading to increased bleeding. $^{78}$

Patients undergoing CABG or trauma surgery with low pre-operative PMV counts are at an increased risk of blood transfusion. ${ }^{39,79}$ Targeting PMV production and clearance to increase circulating numbers may reduce clinically important adverse effects such as bleeding, although larger studies with sampling of blood at multiple time points are required to better delineate the precise perioperative role of PMV. The infusion of PMV may be a potential future treatment for surgery-related bleeding with minimal transmission of pathogens or threat of immune response..$^{80}$

\section{Isolating and studying microvesicles}

Many different methods are currently used to isolate microvesicles from whole blood. The International Society for Extracellular Vesicles is developing protocols for the extraction of Page $\mathbf{1 0}$ of $\mathbf{2 0}$ 
microvesicles to standardise research internationally. ${ }^{6}$ The key process used in the majority of studies is the collection of whole blood, which is then centrifuged twice to obtain plateletpoor plasma (PPP). PPP can be stored at $-80^{\circ} \mathrm{C}$ and thawed prior to analysis by flow cytometry. Although many studies follow an interpretation of these methods, the differences in collection methods and centrifugation protocols have led to variation in reported microvesicle concentrations between studies. ${ }^{51}$

Blood for microvesicle studies should be taken with minimal shear stress; this can be achieved by a slow draw-back into a syringe from a central or arterial line or via venepuncture using a needle larger than 21 gauge. ${ }^{8}$ This blood should preferably be collected into plastic tubes with sodium citrate anticoagulant prior to centrifugation, however other anticoagulants such as lithium heparin can be used. ${ }^{8,81}$

Centrifugation at low speeds may fail to obtain PPP, and overly high speeds can cause microvesicle loss or cause microvesicle doublets to form. Burnouf et al concluded that an initial centrifugation at 2,500g for 15 minutes within two hours of collection, followed by aspiration of PPP and subsequent centrifugation of the supernatant at the same speed and time results in low levels of platelets and less coupling of PMV. ${ }^{82}$

\section{Conclusion}

Pathologies such as Scott syndrome demonstrate, along with clinical and laboratory studies, that PMV have a crucial role in hemostasis. Although PMV could be used, among other predictors of transfusion risk such as pre-operative APTT and hemoglobin, to identify patients at risk of bleeding complications, current methods of identifying PMV populations are inadequate for the rapid and widespread use of PMV for prognostic purposes. However, the increased availability of flow cytometry equipment and refined protocols for isolating and investigating microvesicle numbers has enabled advances in our knowledge of sub-micron hematologic changes throughout cardiac surgery, though there is still much that is not known in this field. Future advances may see the widespread use of pre-operative PMV counts to 
predict peri-operative bleeding complications, and as an assessment of platelet function generally, and transfusion of PMV as prophylaxis or treatment for hemorrhage.

\section{Figure legends}

Figure 1: The hematologic response to endothelial injury leading to the formation of a stable hemostatic plug.

Figure 2: In the non-activated state (left), the platelet membrane is held in asymmetry by movement of phosphatidylserine and phosphatidylethanolamine onto the inner surface. The increase in cytosolic $\mathrm{Ca}^{2+}$ associated with platelet activation results in the loss of asymmetry and the production of PMV.

Figure 3: PMV have an important role within the coagulation cascade. Circled factors bind with PS positive PMV to stimulate coagulation factor activation. Integrin and tissue factor are expressed on receptor-specific PMV membranes and these surface proteins interact with the cascade to enhance coagulation

\section{References}

1. Unsworth-White MJ, Herriot A, Valencia O, et al: Resternotomy for bleeding after cardiac operation: a marker for increased morbidity and mortality. Ann Thorac Surg 59:664-667, 1995

2. Biancari F, Mikkola R, Heikkinen J, et al: Estimating the risk of complications related to reexploration for bleeding after adult cardiac surgery: a systematic review and metaanalysis. Eur J Cardiothorac Surg 41:50-55, 2012 
3. Murphy GJ, Reeves BC, Rogers CA, et al: Increased mortality, postoperative morbidity, and cost after red blood cell transfusion in patients having cardiac surgery. Circulation 116:2544-2552, 2007

4. Cooper CL: Complications of transfusion therapy, in Lake CL, Moore RA (eds). Blood. New York, Raven Press, 1995, pp 319-334

5. Murphy GJ, Pike K, Rogers CA, et al: Liberal or restrictive transfusion after cardiac surgery. NEJM 372:997-1008, 2015

6. Hargett LA, Bauer NN: On the origin of microparticles: From "platelet dust" to mediators of intercellular communication. Pulm Circ 3:329-340, 2013

7. Gustafson CM, Shepherd AJ, Miller VM, et al: Age- and sex-specific differences in bloodborne microvesicles from apparently healthy humans. Biol Sex Differ 6:10-19, 2015

8. Piccin A, Murphy W, Smith O: Circulating microparticles: pathophysiology and clinical implications. Blood Reviews 21:157-171, 2007

9. Satta N, Toti F, Fressinaud E, et al: Scott syndrome: an inherited defect of the procoagulant activity of platelets. Platelets 8:117-124, 1997

10. Matijevic N, Wang YW, Kostousov V, et al: Decline in platelet microparticles contributes to reduced hemostatic potential of stored plasma. Thromb Res 128:35-41, 2011

11. Chargaff $E$, West R: The biological significance of the thromboplastic protein of blood. J Biol Chem 166:189-197, 1946

12. Wolf $\mathrm{P}$ : The nature and significance of platelet products in human plasma. $\mathrm{Br} \mathrm{J}$ Haematol $13: 269-288,1967$

13. Manno S, Takakuwa $\mathrm{Y}$, Mohandas $\mathrm{N}$ : Identification of a functional role for lipid asymmetry in biological membranes: Phosphatidylserine-skeletal protein interactions modulate membrane stability. Proc Natl Acad Sci USA 99:1943-1948, 2002

14. Beleznay Z, Zachowski A, Devaux PF, et al: ATP-dependent aminophospholipid translocation in erythrocyte vesicles: stoichiometry of transport. Biochemistry 32:31463152,1993 
15. van Helvoort A, Smith AJ, Sprong $H$, et al: MDR1 P-glycoprotein is a lipid translocase of broad specificity, while MDR3 P-glycoprotein specifically translocates phosphatidylcholine. Cell 87:507-517, 1996

16. Zwaal RF, Comfurius P, Bevers EM: Mechanism and function of changes in membranephospholipid asymmetry in platelets and erythrocytes. Biochem Soc Trans 21:248-253, 1993

17. Bevers EM, Comfurius P, van Rijn JL, et al: Generation of prothrombin-converting activity and the exposure of phosphatidylserine at the outer surface of platelets. Eur $\mathrm{J}$ Biochem 122:429-436, 1982

18. Zwaal R, Comfurius $\mathrm{P}$, Bevers $\mathrm{E}$ : Surface exposure of phosphatidylserine in pathological cells. Cell Mol Life Sci 62:971-988, 2005

19. McLaughlin PJ, Gooch JT, Mannherz HG, et al: Structure of gelsolin segment 1-actin complex and the mechanism of filament severing. Nature 364:685-692, 1993

20. Bassé $F$, Gaffet $P$, Bienvenüe A: Correlation between inhibition of cytoskeleton proteolysis and anti-vesiculation effect of calpeptin during A23187-induced activation of human platelets: are vesicles shed by filopod fragmentation? Biochim Biophys Acta 1190:217-224, 1994

21. Wiedmer T, Shattil SJ, Cunningham M, et al: Role of calcium and calpain in complementinduced vesiculation of the platelet plasma membrane and in the exposure of the platelet factor Va receptor. Biochemistry 29:623-632, 1990

22. Macey MG, Enniks N, Bevan S: Flow cytometric analysis of microparticle phenotype and their role in thrombin generation. Cytometry B Clin Cytom 80:57-63, 2011

23. Taube J, McWilliam N, Luddington R, et al: Activated protein C resistance: effect of platelet activation, platelet-derived microparticles, and atherogenic lipoproteins. Blood 93:3792-3797, 1999

24. Sinauridze EI, Kireev DA, Popenko NY, et al: Platelet microparticle membranes have 50to 100 -fold higher specific procoagulant activity than activated platelets. Thromb Haemost 97:425-434, 2007

Page 14 of 20 
25. Suades R, Padró T, Vilahur G, Badimon L: Circulating and platelet-derived microparticles in human blood enhance thrombosis on atherosclerotic plaques. Thromb Haemost 108:1208-1219, 2012

26. Berckmans RJ, Nieuwland R, Böing AN, et al: Cell-derived microparticles circulate in healthy humans and support low grade thrombin generation. Thromb Haemost 85:639646, 2001

27. Hrachovinovà I, Cambien B, Hafezi-Moghadam A, et al: Interaction of P-selectin and PSGL-1 generates microparticles that correct hemostasis in a mouse model of hemophilia A. Nat Med 9:1020-1025, 2003

28. Stampfuss JJ, Censarek P, Bein D, et al: Membrane environment rather than tissue factor expression determines thrombin formation triggered by monocytic cells undergoing apoptosis. J Leukoc Biol 83:1379-1381, 2008

29. Holme PA, Solum NO, Brosstad F, et al: Microvesicles bind soluble fibrinogen, adhere to immobilized fibrinogen and coaggregate with platelets. Thromb Haemost 79:389-394, 1998

30. Nieuwland R, Berckmans RJ, Rotteveel-Eijkman RC, et al: Cell-derived microparticles generated in patients during cardiopulmonary bypass are highly procoagulant. Circulation 96:3534-3541, 1997

31. Lacroix R, Dubois C, Leroyer AS, et al: Revisited role of microparticles in arterial and venous thrombosis. J Thromb Haemost 11(Suppl 1):24-35, 2013

32. Rank A, Nieuwland R, Crispin A, et al: Clearance of platelet microparticles in vivo. Platelets 22:111-116, 2011

33. Augustine D, Ayers LV, Lima E, et al: Dynamic release and clearance of circulating microparticles during cardiac stress. Circ Res 114:109-113, 2014

34. Dasgupta SK, Abdel-Monem H, Niravath P, et al: Lactadherin and clearance of plateletderived microvesicles. Blood 113:1332-1339, 2009 
35. Ahsan F, Rivas IP, Khan MA, et al: Targeting to macrophages: role of physicochemical properties of particulate carriers--liposomes and microspheres--on the phagocytosis by macrophages. J Control Release 79:29-40, 2002

36. Matijevic N, Kostousov V, Wang Y, et al: Multiple levels of degradation diminish hemostatic potential of thawed plasma. J Traum 70:71-80, 2011

37. Despotis G, Summerfield MD, Joist JH, et al: Comparison of activated coagulation time and whole blood heparin measurement with laboratory plasma antiXa-heparin concentration in patients having cardiac operations. J Thorac Cardiovasc Surg 108:10761082, 1994

38. Bosch YP, Ganushchak YM, de Jong DS: Comparison of ACT point-of-care measurements: repeatability and agreement. Perfusion 21:27-31, 2006

39. Jy W, Gomez-Marin O, Salerno T, et al: Pre-surgical levels of circulating cell-derived microparticles discriminate between patients with and without transfusion in coronary artery bypass graft surgery. J Thorac Cardiovasc Surg 149:305-311, 2015

40. Herman CR, Buth KJ, Kent BA, et al: Clopidogrel increases blood transfusion and hemorrhagic complications in patients undergoing cardiac surgery. Ann Thorac Surg 89:397-402, 2010

41. Scott DA, Silbert BS, Blyth C, et al: Blood loss in elective coronary surgery: A comparison of centrifugal versus roller pump heads during cardiopulmonary bypass. J Cardiothorac Vasc Anesth 15:322-325, 2001

42. Lubsczyk B, Kollars M, Hron G, et al: Low dose acetylsalicylic acid and shedding of microparticles in vivo in humans. Eur J Clin Invest 40:477-482, 2010

43. Savi $P$, Nurden $P$, Nurden AT, et al: Clopidogrel: a review of its mechanism of action. Platelets 9:251-255, 1998

44. França CN, Pinheiro LF, Izar MC, et al: Endothelial progenitor cell mobilization and platelet microparticle release are influenced by clopidogrel plasma levels in stable coronary artery disease. Circ J 76:729-736, 2012 
45. Hamilos M, Muller O, Ntalianis A, et al: Relationship between peripheral arterial reactive hyperemia and residual platelet reactivity after $600 \mathrm{mg}$ clopidogrel. J Thromb Thrombolysis 32:64-71, 2011

46. Camargo LM, França CN, Izar MC, et al: Effects of simvastatin/ezetimibe on microparticles, endothelial progenitor cells and platelet aggregation in subjects with coronary heart disease under antiplatelet therapy. Braz J Med Biol Res 47:432-437, 2014

47. Weitz JI, Hudoba M, Massel D, et al: Clot-bound thrombin is protected from inhibition by heparin-antithrombin III but is susceptible to inactivation by antithrombin III-independent inhibitors. J Clin Invest 86:385-391, 1990

48. Muriithi EW, Belcher PR, Day SP, et al: Heparin-induced platelet dysfunction and cardiopulmonary bypass. Ann Thorac Surg 69:1827-1832, 2000

49. De La Cruz JP, Carmona JA, Paez MV, Blanco E, et al: Propofol inhibits in vitro platelet aggregation in human whole blood. Anesth Analg 84:919-921, 1997

50. Doğan IV, Ovali E, Eti Z, et al: The in vitro effects of isoflurane, sevoflurane, and propofol on platelet aggregation. Anesth Analg 88:432-436, 1999

51. Lynch S, Ludlam C: Plasma microparticles and vascular disorders. Br J Haematol 137:36-48, 2007

52. Reston JT, Tregear SJ, Turkelson CM: Meta-analysis of short-term and mid-term outcomes following off-pump coronary artery bypass grafting. Ann Thorac Surg 76:15101515,2003

53. Atherton J, Hampshire T, Englyst N, et al: The effect of circulating fresh blood through a micro-bypass circuit on platelet microparticles. Anaesthesia 67: 555, 2012

54. Hornick P, George A: Blood contact activation: pathophysiological effects and therapeutic approaches. Perfusion 11: 3-19, 1996

55. Keyser A, Hilker MK, Diez C, et al: Prospective randomized clinical study of arterial pumps used for routine on pump coronary bypass grafting. Artif Organs 35: 534-542, 2011

Page $\mathbf{1 7}$ of $\mathbf{2 0}$ 
56. Mlejnsky F, Klein A, Lindner J, et al: A randomised controlled trial of roller versus centrifugal cardiopulmonary bypass pumps in patients undergoing pulmonary endarterectomy. Perfusion 2014 Sep 25. pii: 0267659114553283. [Epub ahead of print]

57. Asante-Siaw J, Tyrrell J, Hoschtitzky A, et al: Does the use of a centrifugal pump offer any additional benefit for patients having open heart surgery? Interact Cardiovasc Thorac Surg 5:128-134, 2006

58. Saczkowski R, Maklin M, Mesana T, et al: Centrifugal pump and roller pump in adult cardiac surgery: a meta-analysis of randomized controlled trials. Artif Organs 2012; 36: 668-676, 2012

59. Andersen KS, Nygreen EL, Grong K, et al: Comparison of the centrifugal and roller pump in elective coronary artery bypass surgery - A prospective, randomized study with special emphasis upon platelet activation. Scand Cardiovasc J 37:356-362, 2003

60. Keyser A, Hilker MK, Diez C, et al: Prospective randomized clinical study of arterial pumps used for routine on pump coronary bypass grafting. Artif Organs 35:534-542, 2011

61. Reininger AJ, Heijnen HF, Schumann $\mathrm{H}$, et al: Mechanism of platelet adhesion to von Willebrand factor and microparticle formation under high shear stress. Blood 107:35373545,2006

62. Reininger AJ. Platelet function under high shear conditions. Hämostaseologie 29:21-24, 2009

63. van den Goor JM, van den Brink A, Nieuwland R, et al: Generation of platelet-derived microparticles in patients undergoing cardiac surgery is not affected by complement activation. J Thorac Cardiovasc Surg 126:1101-1106, 2003

64. Nieuwland R, Berckmans R, Rotteveel-Eijkman R, et al: Cell-derived microparticles generated in patients during cardiopulmonary bypass are highly procoagulant. Circulation 96:3534-3541, 1997 
65. Miyamoto S, Marcinkiewicz C, Edmunds LH, et al: Measurement of platelet microparticles during cardiopulmonary bypass by means of captured ELISA for GPIIb/IIla. Thromb Haemost 80:225-230, 1998

66. Gemmell CH, Ramirez SM, Yeo EL, et al: Platelet activation in whole blood by artificial surfaces: identification of platelet-derived microparticles and activated platelet binding to leukocytes as material-induced activation events. J Lab Clin Med 125:276-287, 1995

67. te Velthuis H, Baufreton C, Jansen PG, et al: Heparin coating of extracorporeal circuits inhibits contact activation during cardiac operations. J Thorac Cardiovasc Surg 114:117122,1997

68. Holme PA, Orvim U, Hamers MJ, et al: Shear-induced platelet activation and platelet microparticle formation at blood flow conditions as in arteries with a severe stenosis. Arterioscler Thromb Vasc Biol 17:646-653, 1997

69. Ternström L, Radulovic V, Karlsson M, et al: Plasma activity of individual coagulation factors, hemodilution and blood loss after cardiac surgery: a prospective observational study. Thromb Res 126:e128-33, 2010

70. van den Goor JM, Nieuwland R, van Oeveren W, et al: Cell Saver device efficiently removes cell-derived microparticles during cardiac surgery. J Thorac Cardiovasc Surg 134:798-799, 2007

71. Domen RE: Adverse reactions associated with autologous blood transfusion: evaluation and incidence at a large academic hospital. Transfusion 38:296-300, 1998

72. Vonk AB, Meesters MI, Garnier RP, et al: Intraoperative cell salvage is associated with reduced postoperative blood loss and transfusion requirements in cardiac surgery: a cohort study. Transfusion 53:2782-2789, 2013

73. Park MS, Owen BA, Ballinger BA, et al: Quantification of hypercoagulable state after blunt trauma: microparticle and thrombin generation are increased relative to injury severity, while standard markers are not. Surgery 151:831-836, 2012 
74. Ikeda M, Iwamoto S, Imamura $\mathrm{H}$, et al: Increased platelet aggregation and production of platelet-derived microparticles after surgery for upper gastrointestinal malignancy. J Surg Res 115:174-183, 2003

75. Nomura S, Imamura A, Okuno M, et al: Platelet-derived microparticles in patients with arteriosclerosis obliterans: enhancement of high shear-induced microparticle generation by cytokines. Thromb Res 98:257-268, 2000

76. Fabre O, Vincentelli A, Corseaux D, et al: Comparison of blood activation in the wound, active vent, and cardiopulmonary bypass circuit. Ann Thorac Surg 86:537-541, 2008

77. Starling RC, Moazami N, Silvestry SC, et al: Unexpected abrupt increase in left ventricular assist device thrombosis. NEJM 370:33-40, 2014

78. Straub A, Breuer M, Wendel HP, et al: Critical temperature ranges of hypothermiainduced platelet activation: possible implications for cooling patients in cardiac surgery. Thromb Haemost 97:608-616, 2007

79. Windeløv NA, Johansson PI, Sørensen AM, et al: Low level of procoagulant platelet microparticles is associated with impaired coagulation and transfusion requirements in trauma patients. J Trauma Acute Care Surg 77:692-700, 2014

80. Jy W, Jimenez J, Horstmann L, et al: Endothelial/platelet/erythrocyte-derived microparticles; for treatment of thrombocytopenia caused by chemotherapy; kits. US 8105632 B2 (Patent) 2012

81. Colgate S: The effect of cardiac surgery with cardiopulmonary bypass on the formation of platelet microparticles. MSc thesis, University of Surrey, 2013

82. Burnouf T, Goubran HA, Chou ML, et al: Platelet microparticles: detection and assessment of their paradoxical functional roles in disease and regenerative medicine. Blood Rev 28:155-166, 2014 
Figure 1

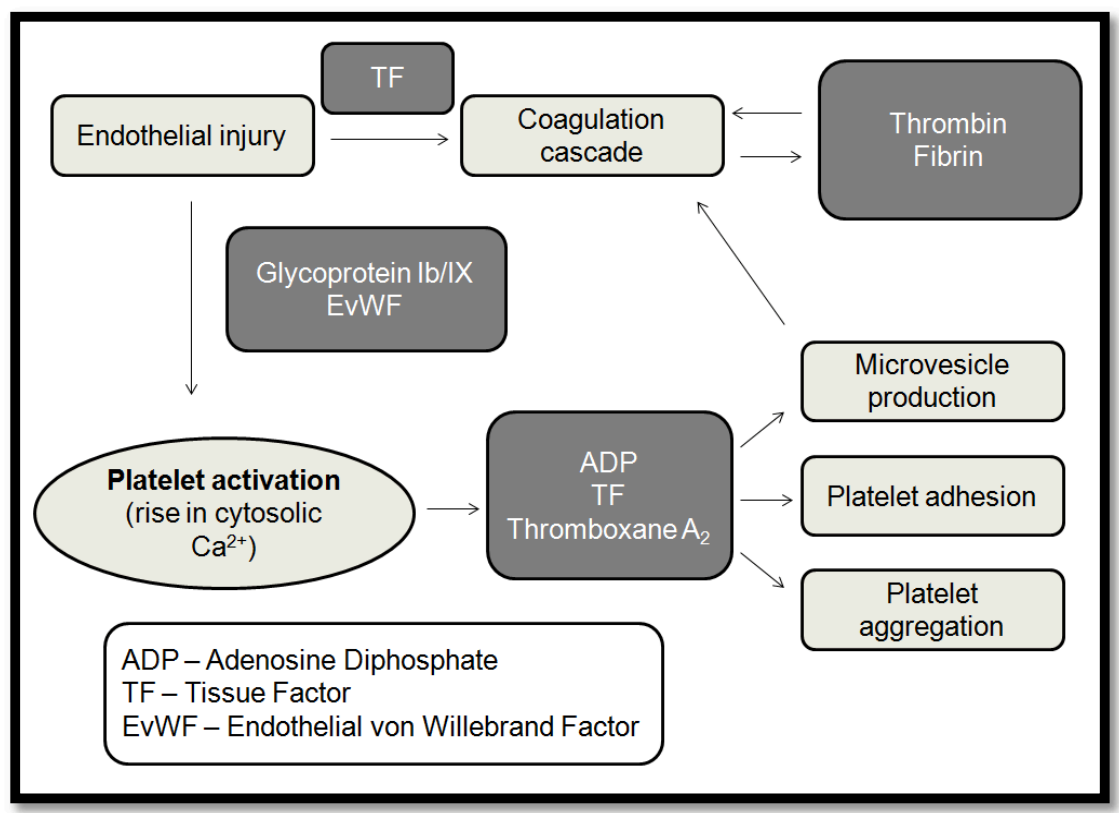


Figure 2

Figure 2

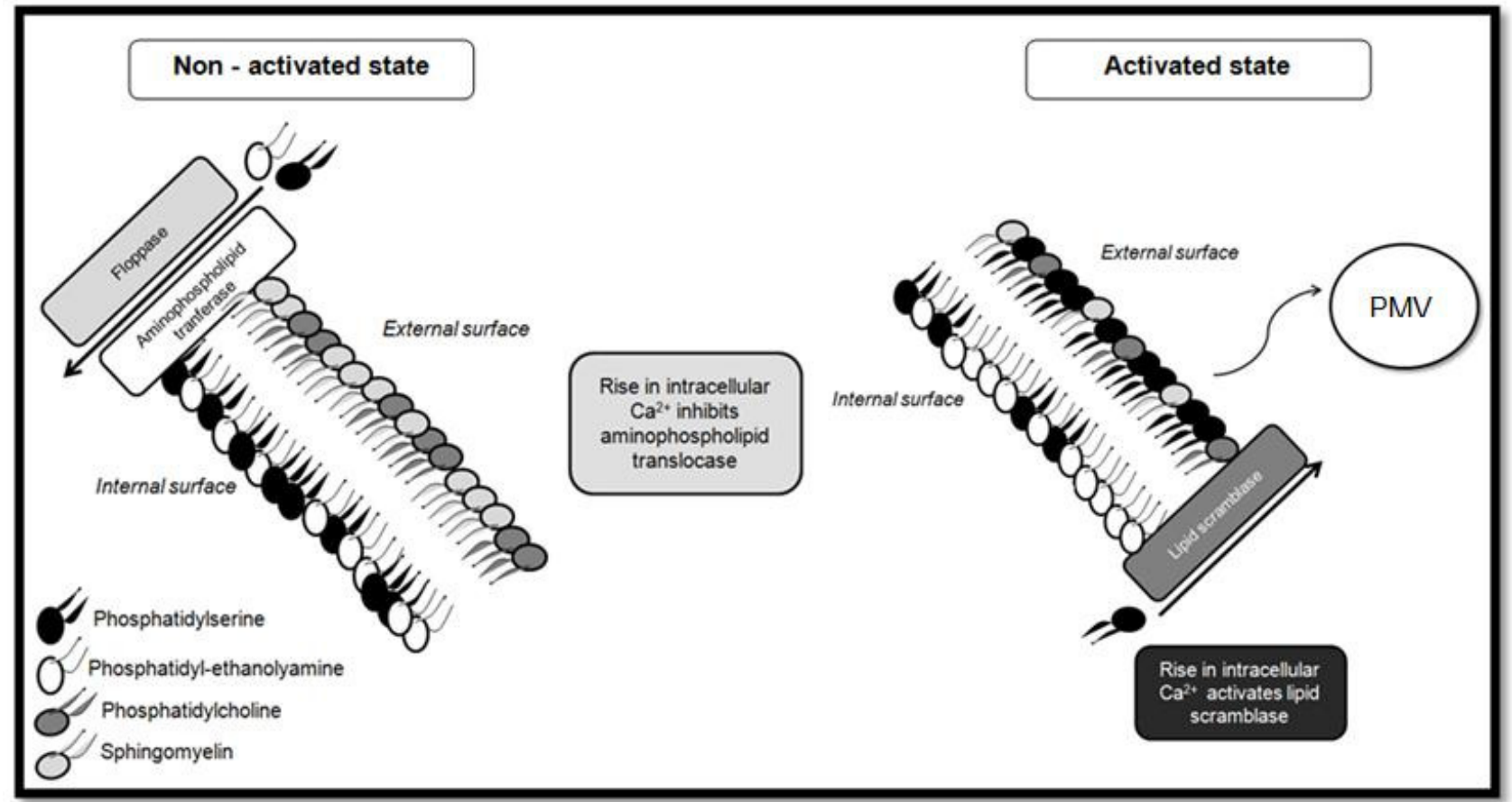


Figure 3

Figure 3

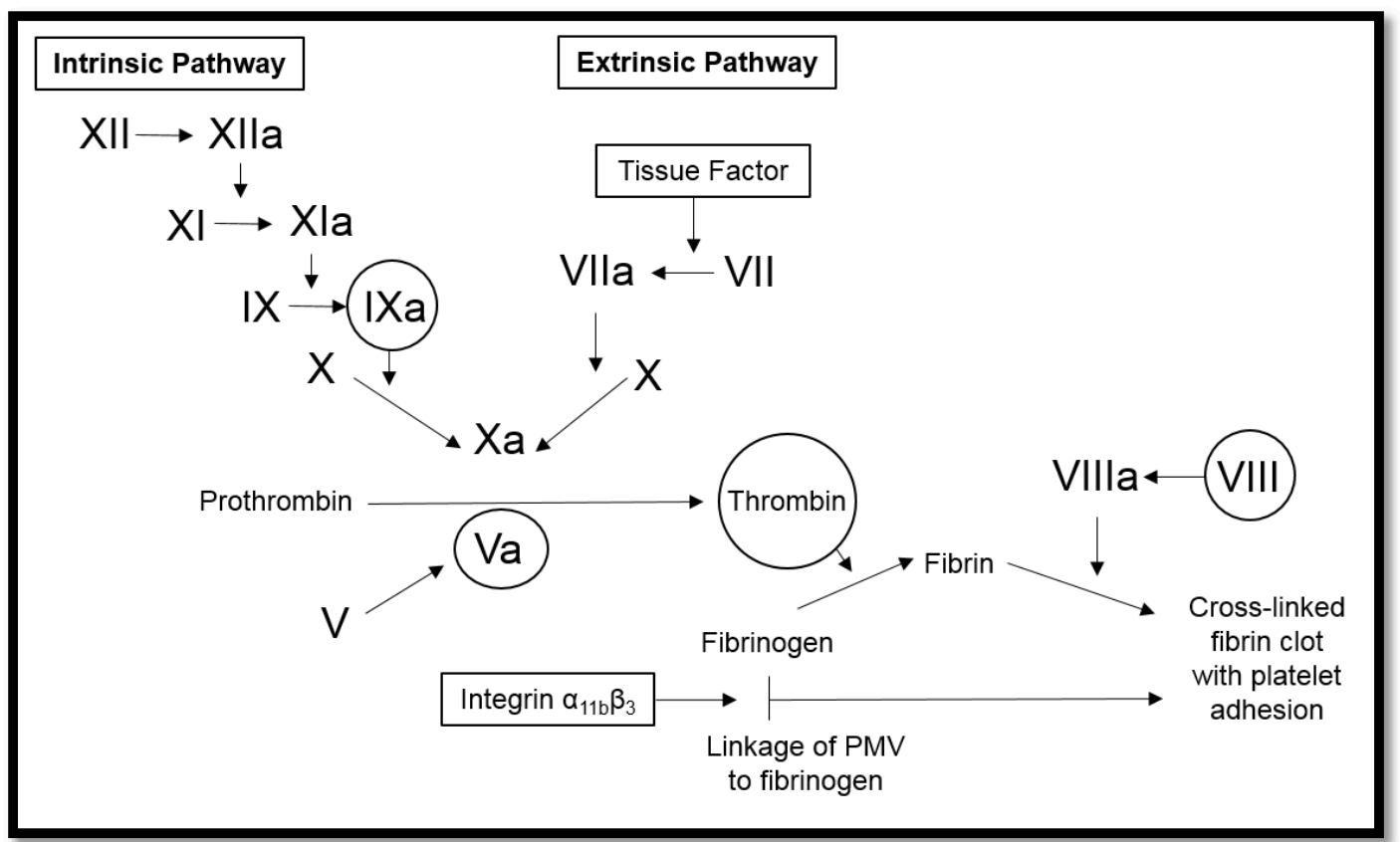

